\title{
11 de Setembro: do terror à injustificada arbitrariedade e o terrorismo de Estado
}

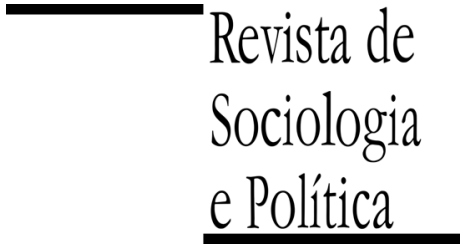

DOI 10.1590/1678-987315235302

\author{
Héctor Luis Saint-Pierre
}

\begin{abstract}
Resumo
O artigo discute a definição comumente aceita de "terrorismo" por considerá-la "extensional" e não intesional. O perigo é que dela se derivam decisões políticas que conduzem ao emprego da força. A falta de objetividade e critérios de aplicação na definição extensional faz dela uma caraterização arbitrária e, de sua aplicação, uma decisão meramente política. Além das questões ontológicas e epistemológicas dessa forma arbitrária de definição, ela obnubila o desenho estratégico e dificulta enfrentar essa ameaça eficazmente. Chama-se a atenção para o uso político cada vez mais frequente desse termo para criminalizar grupos e movimentos sociais contestatários, pois assim se pretende legitimar todo tipo de meios de combate, inclusive a tortura. Por isso propõe-se limitar o emprego do termo "terrorista" como adjetivo que qualifique certas ações violentas e evitar substantivá-la em grupos ou estratégias. Finalmente propõe-se mais uma vez a abordagem "vitimológica" ao estudo do "terrorismo", por sua fertilidade heurística e capacidade explanatória de certas formas de violência.
\end{abstract}

PALAVRAS-CHAVE: terrorismo; 11 de Setembro; Segurança Internacional; violência política; Guerra ao Terror.

Recebido em 1 de Março de 2014. Aprovado em 13 de Julho de 2014.

\section{Introdução ${ }^{1}$}

\begin{abstract}
1 Agradeço de maneira especial ao Proyecto Prometeo de la Secretaríade Educación Superior, Ciencia, Tecnología e Innovación de la República del Ecuador por seu patrocínio a este trabalho, à Fapesp e aos pareceristas anônimos da Revista de Sociologia e Política.

\footnotetext{
2 Discutimos exaustivamente esse conceito em Saint-Pierre e Bigatão (2008). O tema foi retomado e aprofundado em Jobin (2010).
}

O segundo impacto nas torres gêmeas daquele fatídico 11 de Setembro de 2001 não deixava lugar a dúvidas: tratava-se de um ataque terrorista à hiperpotência que até esse momento julgava-se invulnerável. O que ficou claro nesse momento no Brasil foi a falta de acadêmicos especialistas no tema; o que se viu foi um desfile de caras novas e ousadas, das que não se avermelham ao falar do que não sabem, frente às câmeras de TV, para inundar os jornais televisivos com comentários irrelevantemente jornalísticos. Ainda assim, como anteriormente sucedera com a Guerra do Golfo, houve uma sacudidela nos estudos de RI, narcotizados desde o prematuramente declarado "Fim da História" e a incorporação acrítica de conceitos epistemologicamente inconsistentes como o de "unipolaridade"2. O resultado positivo para as RI foi o fortalecimento da área dos estudos de Segurança dando uma nova vitalidade às pesquisas e análises a uma área que, embora tivesse dado origem à disciplina das RI, estava um pouco esquecida e até estigmatizada na academia. Desde então, rios de tinta se gastaram escrevendo sobre "Terrorismo", particularmente sobre o 11 de Setembro - ignorando os tipologicamente semelhantes ataques à AMIA e ao consulado Israelense em Buenos Aires - e sobre o impacto do mesmo na Segurança Internacional. As RI no Brasil, tão vulneráveis que são às modas temáticas da metrópole, introduziram o "terrorismo" como referência obrigatória em suas reflexões da Segurança Internacional, chegando a substituir o obrigatório "Pós-Guerra Fria". Assim produziram-se umas poucas análises relevantes e outras interessantes, a maioria óbvia e jornalística e algumas claramente erradas.

Difícil é imaginar que não foi proposital mas, entre as supérfluas, as mais erradas foram consideradas axiomáticas no cálculo estratégico do Departamento de Defesa norte-americano, o que o levou a definir sua projeção 
${ }^{3}$ Chegou ao derrube de um avião espião norte-americano numa ilha chinesa.

${ }^{4}$ Essa curiosidade foi registrada em Saint-Pierre (2001a).

${ }^{5}$ Sobre esse tema ver o cuidadoso estudo de Montoya (2010).

${ }^{6}$ Os Estados Unidos foram condenados pelo Tribunal Internacional de Justiça da Haya por ato de terrorismo ao fechar com minas o porto de Managua impedindo a entrada de alimentos e medicamentos. Isso foi durante o governo de Donald Reagan, considerado um dos melhores pelos norte-americanos, conforme recente pesquisa. estratégica e condicionar o desenho das políticas externas dos países estrategicamente dependentes do "hegemon" - o chamado "Ocidente". No primeiro discurso depois do atentado e em claro intento por recuperar a tensão do tecido social, abalado pela perda do sentimento de segurança e invulnerabilidade, o presidente George W. Bush declarou uma guerra global contra o "terrorismo" (como se isso fosse estrategicamente possível). Mas foi mais longe ainda. Num paroxismo bíblico, esqueceu da República Popular da China - que para esse então era o alvo estratégico dos Estados Unidos depois de uma série de altercados que tinham subido drasticamente a tensão entre ambas as potências ${ }^{3}$ - para provocar uma divisão maniqueísta do mundo entre bons e maus e entre os quais só caberia a guerra e a morte como relacionamento. Arrebatado por um frenesi de exorcista, estremeceu o mundo ameaçando aos neutrais de serem combatidos se não se engajassem nessa guerra absurda. O resultado desse ataque terrorista (o discurso presidencial de Bush) teve efeitos imediatos: Arafat, naquele momento líder da OLP, ofereceu sangue palestina para socorrer os feridos das torres e até Fidel Castro se dispôs a enviar uma brigada de médicos para auxiliar o resgate às vítimas ${ }^{4}$. Nem Arafat nem Castro morriam de amor pelo Bush, mas sim de medo, ante o leque de possibilidades de ação de um fanático radical no comando do país mais poderoso do mundo.

Esse arrebato fanático teve consequências importantes para a Segurança Internacional e também para acelerar o declínio da hiperpotência como referência estratégica internacional. Longe de ter sido um "divisor de águas da Segurança Internacional", como se precipitaram a cantar alguns pavões das RI, ávidos da efêmera fama televisiva, aquela decisão jogou os Estados Unidos no que chamei "década de sonambulismo estratégico" que, para uma potência acostumada a orientar a segurança global, resultou numa patética perda de prestígio. Nessa década perdeu-se a compostura moral e se estremeceu a ordem nomológica internacional, admitiu-se a tortura (considerada internacionalmente crime imprescritível) como forma de combater o terrorismo e, na pressão ex post facto, conseguiram que a Organização das Nações Unidas (ONU) admitisse uma leitura distorcida do conceito de "ataque preventivo" contra pequenos e indefesos países ${ }^{5}$. Com essa atitude prepotente e insensível às regras de convivência internacional, atuando por cima e contra pareceres da ONU, o governo do único país condenado por "terrorismo" pelo Tribunal da Haya ${ }^{6}$ massacrou povos, rapinhou culturas milenares, desestabilizou regiões e semeou o ódio, aumentando a insegurança no mundo. Como afirmou a presidenta do Brasil, Dilma Rousseff, na abertura da Assembleia Geral das Nações Unidas, o mundo ficou mais inseguro e os "terroristas" se multiplicaram e alastraram por várias partes do mundo (Brasil 2014). Mas, do ponto de vista estratégico, o empenho norte-americano limitou-se a um acionar meramente reativo e desordenado, comandado pelo capricho dos terroristas, seguindo as ondas ditadas pela "guerra contra o terror" e esquecendo daquele que era o sentido objetivo da orientação estratégica na mudança de frente de projeção dos Estados Unidos depois do fim da Guerra Fria e antes do 11 de Setembro, isso é, a China.

$\mathrm{Na}$ estratégia, assim como na política e pelas mesmas óbvias razões, não existe o espaço vazio: como no jogo oriental Go, o espaço é o objeto da disputa. Assim, sem discursos inflamados, movimentos grotescos, nem gestos histriônicos, a China seguiu seus desígnios estratégicos de longo prazo, apoiando com infraestrutura a construção de institucionalidade na África; reclamando sua estatura estratégica no Mar da China; dissolvendo o grande porta-aviões fixo dos Estados Unidos junto a sua costa, ao incorporar na sua estratégia econômica ao empresariado taiwanês; e aumentando paulatina e consistentemente sua presença no mercado latino-americano. Nesse mesmo tempo, os Estados Unidos feria de morte o Estado Iraquiano - seu mais importante aliado na luta contra o terrorismo islâmico - e pisoteava uma cultura milenar, para deixar no seu 
lugar a devastação, a desordem política e social, a miséria e, sobretudo, o ódio pelo invasor; embrenhou-se numa improvável guerra no Afeganistão contra os outrora "guerreiros da liberdade" e agora meros "terroristas" que eles próprios armaram, financiaram e treinaram contra as tropas da antiga União Soviética. Desmentindo a declaração do Secretário de Defesa, Donald Rumsfeld, que assegurou que os Estados Unidos tinham condições de manter combate em quatro cenários bélicos diferentes simultaneamente, hoje suas tropas se retiram do Iraque e do Afeganistão carregando a vergonha de mais duas derrotas militares para somar aos fracassos que resultaram de todos ${ }^{7}$ os engajamentos bélicos empreendidos pela hiperpotência depois da Segunda Guerra Mundial.

\section{Em torno de uma definição de "terrorismo"}

${ }^{7}$ Talvez descontando, como tristes exemplos, as vergonhosas intervenções em Granada e Panamá.

\footnotetext{
${ }^{8}$ Distinção essa colocada com a veemência schmittiana que cristaliza e define o âmbito do político. A frase do presidente norte-americano "quem não estiver conosco está contra e será combatido" expressa de maneira descarnada e empírica a formulação que Schmitt (1984) analisa teoricamente. Discutimos detidamente essa concepção schmittiana em Saint-Pierre (1991) e em Saint-Pierre (2002).
}

As imagens transmitidas globalmente em tempo real do impacto do segundo avião nas torres não deixou dúvidas, tratava-se do ataque terrorista exitoso mais registrado da história. Usando aviões de passageiros e com a determinação de transformar suas vidas em vetores da morte, um pequeno grupo de militantes do que depois se conheceu como Al Qaeda - produzia o mais emblemático, devastador e documentado ataque terrorista da história e, ao mesmo tempo, acabava com o mito da invulnerabilidade do território da hiperpotência. Em pouco tempo os norte-americanos passaram da incredulidade ao espanto, e então desse ao terror, ao imaginarem-se no lugar das vítimas, e do terror ao desamparo, ao perceber que a fabulosa máquina bélica que fora montada com seus impostos, a mais poderosa que a história conhecera, com capacidade de projetar seu poder convencional e nuclear a qualquer ponto do mundo, não era capaz de garantir a segurança dos seus cidadãos na sua própria casa. Não apenas mostrava-se incapaz de evitar que uma dúzia de fanáticos colocasse o país em pânico, mas seu arbitrário acionar como gendarme do mundo provocava o ódio e atraia a fúria da vingança para dentro das fronteiras nacionais.

Esses ataques recolocaram a análise do fenômeno das relações de força e as questões de Segurança Internacional numa posição destacada na agenda dos estudos das Relações Internacionais e, mais particularmente, ao fenômeno do terrorismo no centro da mesma, como catalisador dos arranjos de forças na sua função de critério para distinguir amigos de inimigos ${ }^{8}$ e como orientador principal nas decisões políticas da Segurança Internacional. Seja como objeto de análise dos estudos das Relações Internacionais, seja como justificativa da frente de projeção estratégica global do esforço bélico da hiperpotência, a emergência do fenômeno do terrorismo exige uma reflexão "polemológica". Isso obriga os estudiosos desses temas a intentar recuperar algumas das manifestações empíricas com que o fenômeno apareceu na história, assim como aquelas reflexões teóricas que esses fenômenos concitaram sobre o "terror" e o "terrorismo". A partir desse esforço, talvez seja possível se aproximar de uma definição de "terrorismo" que impeça o emprego extensional, arbitrário e político do mesmo, que justifique, internacionalmente, punições desproporcionais contra países considerados "terroristas" ou do "eixo do mal" em qualquer parte do planeta e, internamente, a repressão indiscriminada e o atropelo aos direitos humanos e o Estado de Direito por uma guerra não definida e mal formulada.

Na verdade, o emprego dos atos terroristas não é uma novidade. Ele é tão antigo quanto a própria guerra que acompanha o homem desde sempre. Os Estados, os exércitos, as etnias, os grupos e os homens isoladamente têm empregado o expediente de ações terroristas como forma de desencorajar seus inimigos para diminuir sua resistência e facilitar a vitória. A tétrica característica que recobre com um manto de novidade esse velho flagelo é sua atual e crescente internacionalização. A característica internacional do terrorismo pode 
${ }^{9}$ É bom lembrar que a guerra de resistência à opressão ou à agressão é a única considerada legítima pela $\mathrm{ONU}$, e todos os meios empregados nela também serão legítimos. ser nova, mas não surpreende. Com efeito, num mundo cuja novidade consiste na hegemonia incontestada de uma superpotência com interesses globais, onde a realização desses interesses dificilmente se completa sem ferir outros, a colheita de ódio torna-se inevitável. Quando nenhuma ação diplomática é eficiente para defender interesses postergados, quando nenhum organismo internacional é suficientemente forte e independente como para distribuir justiça entre interesses afetados, quando nenhuma forma convencional de violência é eficaz para defendê-los, fica aberta a porta para que o ódio se manifeste de maneira incontrolável e muitas vezes irracionalmente com relação aos seus objetivos. Na Guerra do Golfo ficou claro, como observou La Maisonneuve (1998), que qualquer exército convencional é impotente frente à manifestação pretoriana da superpotência. Ante essa constatação, qualquer pretensão estratégica tem apenas dois caminhos para “igualar” suas possibilidades: o poder nuclear, para quem possa desenvolver essa tecnologia ou comprá-la, demasiado longe para os países pobres, ou o recurso à guerra assimétrica, isso é, a tática da guerrilha e as ações terroristas. Especialmente as ações terroristas, pela sua simplicidade operativa, baixo custo, efeito devastador, potencial comunicativo e facilidade de internacionalização, torna-se uma alternativa tentadora para manifestar o ódio por parte de grupos fanáticos ou de expressão bélica legítima para grupos oprimidos ou regiões militarmente invadidas 9 . Com respeito à internacionalização do terror: ante uma hegemonia planetária com interesses globais o terreno de operações da guerra assimétrica torna-se também global. E assim, "afastamo-nos das guerras convencionais, limitadas aos especialistas, que podiam constituir uma forma de continuação da política por outros médios; estamos na era da guerra de todos contra todos" (idem, p. 184).

A política externa dos Estados Unidos transformou os atentados do 11 de Setembro no pivô de uma nova ordem mundial em função da exigência de um realinhamento de alianças e projeções estratégicas com o objetivo de oferecer combate contra um "terrorismo" não definido ou, o que é pior, mal definido. De fato, a frente de projeção estratégica que polarizou a correlação de forças internacionais durante a década de combate ao terrorismo (a década do sonambulismo estratégico) foi um fenômeno difuso e global que, em sua ambiguidade conceitual, tornou-se politicamente versátil para identificar o inimigo em três planos diferentes, substituindo a função que desempenhou o conceito polemológico do "comunismo" durante toda a Guerra Fria. Esse conceito, deliberadamente vago e ambíguo, permite:

(i) Por um lado, delimitar a frente internacional, ao definir uma inimizade global com o consequente arco de alianças intencionais que divide o mundo em duas esferas eticamente antagônicas e inconciliáveis, o lado do "bem", representado pelos que concordam com a arbitrária conceptualização extensional de "terrorismo", isso é, com as listas elaboradas pelo Departamento de Estado norte-americano, e que se comprometem na guerra sem quartel contra esse inimigo; e o lado do "mal", representado pelos considerados "terroristas", "Estados canalhas", mais todos aqueles países que os apoiem, como também aqueles que pretendam se manter à margem de uma guerra que por definição da hiperpotência não admite neutrais;

(ii) Por outro lado, essa ambiguidade de definição e o caráter difuso do inimigo, somado à imprevisibilidade das suas ações e a localização global na qual poderão emergir para despejar sua carga letal, obriga os governos a permanecerem alertas à manifestação nacional do "terrorismo", delimitando, desse modo, a fronteira interna da guerra. Por trás de cada pacato cidadão pode se esconder um impiedoso terrorista, detrás de cada homem e mulher se potencializa uma eventual ameaça que obriga à desconfiança de todo patrício, nacionalizando a inimizade internacional do terror. Essa frente de combate permite aos governos, no limite e conforme suas necessidades de gover- 
${ }^{10}$ Como foi proposto no Congresso brasileiro para enquadrar manifestações durante a Copa do Mundo de 2014

11 Note-se que aqui se trata de "intensionalidade" e não de "intencionalidade", esse é um conceito longamente discutido nos tratados de lógica quando tratam de definições, que são classificadas como extensionais e intensionais.

12 Destaquei a face terrorista dessa guerra contra o terrorismo em Saint-Pierre (2004). nabilidade, caracterizar quaisquer manifestações de descontentamento social como "atos terroristas" 10 e os movimentos sociais que os promovem como "grupos terroristas";

(iii) Finalmente, embora vago e difuso, esse conceito parece possuir a característica quase mágica de poder se condensar materialmente em algum país representativo do decretado "eixo do mal" ou de seus aliados. Isso cria um excelente cenário bélico convencional sobre o qual a superpotência pode exibir sua capacidade imperial despejando armamento bélico convencional (e não convencional, como bombas de racimo e fragmentação), de maneira a exibir ameaçadoramente a tecnologia do seu requintado arsenal militar para potenciais, e muitas vezes obrigados, compradores.

O uso jornalístico e abusivo do conceito de "terrorismo internacional" não leva em conta uma distinção academicamente iniludível entre os critérios especificamente definicionais e os pragmático-políticos. Por exemplo, houve outros notórios incidentes no Cone Sul, como o atentado à Embaixada de Israel na Argentina e, posteriormente, à Asociación Mutual Israelita Argentina (AMIA), porém, não foram considerados "terrorismo internacional". Não se solicitou, como depois do 11 de Setembro, o apoio internacional à luta contra o terrorismo. Não foram investigados depósitos bancários nem se recorreu a uma conferência internacional de inteligência. Não houve solidariedade internacional: o perigo ainda parecia demasiado remoto dos interesses "ocidentais". Mas quanto o impacto foi no coração do sistema financeiro internacional e no centro do sistema nervoso da pletora que o defende, ficou claro que não existe escudo nuclear suficiente nem hiperpotência invulnerável ao acionar do terror, que qualquer potência pode ser alvo de um ataque terrorista. Assim a comunidade internacional produziu um ato condenatório e decidiu combater solidariamente na "guerra" contra o "terrorismo", independentemente do peso semântico que pudesse ocultar esse conceito.

O terrorismo pode ser combatido, mas precisamente por isso e para isso deve ficar perfeitamente claro o seu escopo definicional, assim como devem ser explicitados os critérios de aplicação dessa definição e discutidos os meios mais eficazes para levar a cabo esse combate. Há duas formas clássicas possíveis para definir, aquela que o faz intensionalmente ${ }^{11}$, por um atributo específico do definido, como o aristotélico "gênero próximo e diferença específica", ou extensionalmente, isso é, pela numeração extensiva dos elementos que fazem parte do conjunto definido. A precaução sobre os critérios para definir "terrorismo" fica dramaticamente justificada quando aquela potência hegemônica, por um critério puramente extensional de terrorismo, publica as famosas "listas" dos grupos considerados "terroristas", e contra os quais os governos solidários poderão ver-se compelidos a combater.

A importância destas definições reside no fato que elas delimitam a frente de combate internacional ao terrorismo e essas listas, definidas arbitrariamente, provocam pânico ${ }^{12}$ nos povos, confusão nas políticas de defesa e erros fatais nas decisões estratégicas. Nessas listas, que por obedecer a critérios extensionais estão sujeitas a caprichos políticos, são citados grupos políticos armados, alguns empregando métodos guerrilheiros, que disputam o monopólio da violência em países da região, como por exemplo as FARC. Pode-se argumentar que as FARC praticam atos terroristas, ainda assim, é discutível se o emprego de ações táticas terroristas incluam a quem as pratica na definição de terrorista. Táticas terroristas são frequentemente usadas, em muitos casos por exércitos regulares, inclusive o da Colômbia, mas isso não os tornam terroristas, como não tornou terrorista a George Bush sua frase claramente terrorista "quem não estiver do lado dos Estados Unidos estará contra e será combatido". Não obstante a óbvia importância de uma definição unívoca, nenhuma das que 
atualmente estão em voga satisfaz os critérios de clareza e objetividade que exige uma análise acadêmica séria e desinteressada. Muitos autores tentaram explicar o manto de nevoa que encobre a definição do terrorismo, como mostraremos a seguir.

\section{Dificuldades para definir "terrorismo"}

Uma das primeiras dificuldades que surge na hora de definir "terrorismo" decorre da característica eminentemente subjetiva do terror. Tendo como propósito "destruir a moral de uma nação ou de uma classe, socavar sua solidariedade" (Walzer 2001, p. 269), o terrorismo é uma forma de violência cuja realização se objetiva no âmbito psicológico do indivíduo. Seu efeito é uma disposição psicológica e portanto íntima: o terror. Essa natureza subjetiva, para Wilkinson (1977, p. 43), constitui precisamente um dos problemas fundamentais que se apresenta na hora de tentar defini-lo. O medo é um fenômeno subjetivo e não há como determinar objetivamente um umbral crítico único para o terror, que dependerá de fatores tão variáveis como os pessoais, os funcionais e os culturais. Mas o problema no caminho de uma definição convincente de terrorismo é que essa incerteza é precisamente o objetivo estratégico dessa peculiar forma de violência, como adverte Reinares (1998, p. 16):

\footnotetext{
“A intenção de suscitar reações emocionais tais como ansiedade, incerteza ou amedrontamento entre os que formam parte de um determinado agregado da população, de maneira que resulte factível condicionar suas atitudes e dirigir os seus comportamentos numa direção determinada, prima nos atos terroristas sobre o desejo de causar danos tangíveis a pessoa ou coisas".
}

Outra das dificuldades para definir de maneira objetiva e clara o conceito de "terrorismo", apontada por vários autores que refletiram sobre esse tema, é o sentido pejorativo com que pragmaticamente empregou-se essa palavra ao longo da história. A aplicação da palavra "terrorismo" vem sempre acompanhada de um juízo de valor e, portanto, também subjetivo: o grupo que para alguns é terrorista para outros poderá estar formado por guerreiros da liberdade. Em geral, o terrorista é sempre o "outro", independentemente de que, como advertira Trotsky (1973), depois de uma luta prolongada, os meios e táticas de combates empregados por ambos os lados da linha de frente sejam essencialmente os mesmos, "os inimigos aprendem um do outro: rejeitam o inútil e remedeiam as carências" (idem, p. 122). Esse fato dificulta a adoção de um conceito objetivo, unívoco, aceito por todos e que possa permitir o desenvolvimento de uma teoria do terrorismo. Frequentemente se emprega o apelativo "terrorista" para desumanizar ou desacreditar adversários políticos ou qualquer oposição ao regime estabelecido. O apelativo de "terrorista", por um lado, parece justificar o emprego de todos e quaisquer meios na sua eliminação - inclusive a tortura - e, por outro, procura abrir uma brecha entre o grupo assim considerado e a população em geral evitando a simpatia dessa com a causa daquele e um eventual apoio. Por outro lado, parece haver uma certa dificuldade generalizada para considerar como "terroristas" alguns dos atos de violência e comportamentos regulares, oficiais, aqueles praticados pelos governos e, na maioria dos casos, em nome da ultima ratio do Estado. Todavia, essa dificuldade desaparece quando se trata de caracterizar o comportamento de indivíduos que manifestem sua inconformidade contra o regime ou o governo, ou de algum grupo que se insurja contra o monopólio da violência do Estado, mesmo que seja contra daqueles Estados que não duvidariam em empregar táticas terroristas contra a sociedade. Como diz Walzer (2001, p. 269), "a imposição sistemática do terror sobre populações inteiras é uma estratégia que se utiliza tanto na guerra convencional como na guerra de guerrilhas e é um recurso que empregam tanto os governos estabelecidos quanto os movimentos radicais." 
$\mathrm{Na}$ verdade, essa dificuldade parece fundada no preconceito daqueles que forçam a distinção entre força e violência e que já apontáramos em outro lugar (Saint-Pierre 2000). Hobbes (1983), por exemplo, reivindicava todo o poder e força para o soberano. Poder e força, dois elementos frequentemente confundidos porque ambos concorrem para o exercício de governo. "Trata-se pensava Arendt - de uma triste reflexão sobre o atual estado da Ciência Política o fato de que nossa terminologia não distinga entre palavras-chaves tais como 'poder', 'força', 'autoridade', e, finalmente 'violência'” (Arendt 1985, p. 23). Confusão que a autora atribui ao fato de que "poder, força, autoridade, violência - nada mais são do que palavras para indicar os meios pelos quais o homem governa o homem; são elas consideradas sinônimos por terem a mesma função" (idem, p. 23). Para Arendt, o poder, diferentemente da violência, se relaciona com o número. Poder é a capacidade de agir em uníssono, em comum acordo, o que o torna um fenômeno quantitativo. Por sua vez a violência, para a autora, reveste-se de caráter instrumental. Para ela, o poder é o contrário da violência, a essa se recorre quando não se conta com aquele: "A forma extrema do poder resume-se em 'Todos contra Um', e a extrema forma de violência é 'Um contra Todos"” (idem, p. 22).

Contrária à posição de $\mathrm{H}$. Arendt, pode-se destacar uma corrente filosófica que considera a violência como a essência da política, sua verdadeira natureza. Pode-se datar o começo dessa corrente, que passou a ser conhecida como "Filosofia da Força", no século XVI, e podemos nomear a Maquiavel como seu fundador. Para essa reflexão o eixo fundamental da política é o exercício da força guiado pela óptica do príncipe, do Estado ou dos interesses de classe. Nela encontramos, entre outros, pensadores representantes de posições tão diversas como Hobbes, Marx, Weber, Lênin, Trotsky, Carl Schmitt, Raymond Aron, Morgenthau, Carr, Waltz entre muitos outros. Dentro dessa corrente e em oposição radical a Arendt, Georges Sorel propõe uma definição terminológica que distingue força e violência por critérios ideológicos, tornando supérflua a obscuridade quantitativa da definição daquela:

\footnotetext{
"Os termos força e violência são empregados ora ao se falar dos atos da autoridade, ora ao se falar dos atos de revolta. É claro que os dois casos dão lugar a consequências bem diferentes. Sou da opinião de que seria mais vantajoso adotar uma terminologia que não resultasse em ambiguidade e de que se deveria reservar o termo violência para a segunda acepção. Diríamos portanto que a força tem por objetivo impor a organização de uma certa ordem social na qual uma minoria governa, enquanto a violência tende à destruição dessa ordem. A burguesia empregou a força desde o início dos tempos modernos, enquanto o proletariado reage agora contra ela e contra o Estado pela violência" (Sorel 1992, p. 195).
}

Embora a violência vise à destruição da ordem, ela não é intrinsecamente desordenada. Em outras palavras, não devemos, baseados na formulação de Arendt, supor que, porque a força é institucional e racional, a violência só possa ser irracional. Pelo contrário, a violência não é necessariamente um transbordo descontrolado das forças reprimidas; ela pode ser a canalização estratégica dessa energia com o objetivo meridianamente claro e racionalmente deliberado da tomada do poder do Estado. A racionalidade da violência não deve ser procurada na sua peculiar natureza (desse ponto de vista não há diferença com a força institucional: nenhuma violência é racional na sua essência), mas pode ser avaliada nos resultados substantivos de sua aplicação e na adequação dos meios - racionalidade da ação, para Weber - empregados para a realização dos fins propostos.

Essa distinção entre a pretensa racionalidade da força dos governos, por um lado, e a irracionalidade da violência individual que se atira contra aqueles, por outro, é uma das maiores dificuldades para uma definição objetiva de terro- 
rismo ou para reconhecer, em algumas formas de domínio pela força do governo, claras manifestações de terrorismo. Esse fato não passou inadvertido para Wardlaw (1994), quem, tentando explicar a tendência generalizada a classificar como força a ação dos governos e de terrorismo a dos indivíduos, aponta que os primeiros servem-se de recursos substanciais e títulos bem reconhecidos pela sua legitimidade, enquanto que os indivíduos não podem reivindicar igual legitimidade e caracterizam-se pelos seus escassos recursos e modos de violência pobres. Mas por outro lado, esse autor afirma que um forte motivo para não considerar o acionar dos governos como terrorismo e sim a ação contra estes são as formas como a própria sociedade percebe a diferença:

\begin{abstract}
“A primeira delas é a representação dos atores da nação-estado como seres racionais cujas ações servem a um fim maior. Fomenta-se a impressão de pessoas com autodomínio, idéias lógicas e sentido da responsabilidade, impressões que se reforçam com os estilos de vida do conservadorismo e com qualidades atrativas. Pelo contrário, o ator, que é o terrorista individual, mostra-se como irracional, impulsionado por uma mente insana e com propósitos egoístas e de destruição ilógica. A essa diferença contribuem ainda mais as armas que cada um pode escolher e a forma em que as levam [...]. O soldado pode-se se descrever como um indivíduo controlado que leva legitimamente a sua arma às vistas de todo o mundo. [...] A pessoa que coloca uma bomba carece dessa legitimidade. A bomba coloca-se secretamente, tem efeitos imprevisíveis. [...] Assim, a violência do terrorismo oficial está coisificada e legitimada, mas não a do indivíduo" (idem, pp. 44-46).
\end{abstract}

Ante a divulgação das imagens dos atentados de Nova York, refletindo plasticamente sobre o ponto a que pode chegar a ira "irracional" dos terroristas "islâmicos", passou quase inadvertida a atitude terrorista do presidente da maior superpotência que o mundo já conhecera ameaçando "a todos aqueles países que não estivessem do lado dos Estados Unidos". Para o olhar eletrônico do mundo, a redução a escombros da milenar cultura iraquiana e do miserável Afeganistão pareceu uma resposta "racional", adequada e "justa" pelo que os norte-americanos sofreram. Encontrar-se-á sempre algum jurista que consiga argumentar a favor da "racionalidade" dos tribunais excepcionais e da suspensão dos direitos individuais nos Estados Unidos para preservar a "ordem democrática". Não faltarão sofismas para justificar a "racionalidade" do emprego de quaisquer meios, até os mais repulsivos para qualquer critério humanitário, para defender a civilização ocidental e a democracia, dificultando ainda mais o acesso acadêmico, sem preconceitos nem juízos valorativos, ao fenômeno do terrorismo. Depois de tudo, como diz Wardlaw (idem, p. 44), "a coisificação e legitimação do terrorismo oficial permite condenar o terrorismo individual como moralmente repugnante e não reconhecer em absoluto o terrorismo oficial ou aceitá-lo como duro, mas necessário".

Finalmente, parece haver uma clara intencionalidade política para não definir nem se importar por discutir critérios objetivamente aplicáveis para se referir ao fenômeno do terrorismo. Perpetuar a ambiguidade desse termo mantido em sentido vago permite a quem dispõe da força se dar o direito de aplicá-lo conforme suas necessidades e de usar todos os meios de combate, como suspender a privacidade do indivíduo controlando sua comunicação e atividades, a infiltração e espionagem, a prisão ilegal, os julgamentos extra legais, o sequestro, a tortura e o assassinato. Com a aplicação do termo a grupos ou movimentos sociais, religiosos ou étnicos, pretende-se amedrontar os mesmos e inibir seu acionar. Assim foram enquadrados movimentos como o Movimento dos Sem Terra no governo de Fernando Henrique Cardoso no Brasil, as FARC-EP durante o mandato de Uribe na Colômbia, as manifestações de protesto durante a Copa do Mundo de 2014 no governo Dilma Rouseff, os grupos políticos palestinos pelos meios ocidentais que fizeram o mesmo com os separatistas 
ucranianos. Essa é a forma mais covarde de deslegitimar movimentos e de abrir a Caixa de Pandora da repressão sem qualquer contenção ética ou moral.

O manto de preconceito que ainda encobre e impede uma teoria acadêmica sobre o terrorismo, a gravidade da situação internacional, impelida a uma "guerra global" contra um inimigo invisível, a necessidade de combater consciente e eficazmente o flagelo do terrorismo, as exigências éticas e políticas que devem orientar os métodos empregados nesse combate e a urgência de discutir critérios claros para definir esse fenômeno justificam um pequeno exercício teórico em torno do conceito de "terrorismo" tentando tornar mais nítidos os seus contornos e firme o núcleo duro da sua definição.

\section{Análise do terrorismo}

${ }^{13}$ Entre outros, Saint-Pierre (2004, 2009) e vários artigos e matérias em jornais brasileiros.
Publiquei minha primeira análise do tema do terrorismo no livro A política armada (Saint-Pierre 2000). Ali propus uma aproximação vitimológica à definição do terrorismo, mais precisamente, considerando o peculiar critério com que o terrorista seleciona a sua vítima. Os atentados do 11 de Setembro e suas consequências convocaram novamente minha reflexão sobre esse tema. A constatação da falta de conceptualização adequada sobre "terrorismo" com que a mídia mundial cobria aqueles acontecimentos (e continua a fazer em outros cenários pelo mundo), assim como a confusão e pânico que essa inadequação provocava na opinião pública em geral, convenceram-me a retomar aquela conceptualização, aprofundá-la e melhorá-la, e desde então tenho publicado alguns trabalhos ${ }^{13}$ que abonam o presente escrito da forma que tratarei de expor aqui.

O terrorismo é uma forma de violência cujo efeito realiza-se no âmbito psicológico do indivíduo (Wardlaw 1984; Reinares 1998). Seu objetivo é produzir uma íntima reação no indivíduo: o terror, um pavor incontrolável. O terrorismo é um ato de violência que provoca uma ação social, isso é, constitui uma relação de força. Como relação de força, pode ser analisada nos três níveis nos quais normalmente se manifesta, tratando-se de identificar em cada um deles os objetivos aos quais o acionar do terrorismo se devota:

(i) Nível tático: é o mais visível de toda relação de força, é sua expressão concreta, a aplicação direta da força, o combate, a "gramática da guerra" como diria Clausewitz. Nesse nível, o objetivo visado pelo terrorismo é provocar o maior dano possível. Matar, mutilar, com a maior visibilidade e crueldade possíveis, expressado com os requintes de qualquer meio. Desde facas até bombas, passando por todos os tipos de armas, convencionais ou não, são empregadas para mostrar que não há limite para o seu acionar. $\mathrm{O}$ emprego epistolar da bactéria antraz nos Estados Unidos, nos dias que seguiram aos atentados do 11 de Setembro, ou o gás zarin, utilizado no metrô de Tóquio, são exemplos de que armamento químico, biológico e eventualmente nuclear, se caísse em suas mãos, poderia fazer parte do arsenal do terror para provocar o maior dano possível e obter a maior visibilidade;

(ii) Nível estratégico: o objetivo estratégico de todo exercício de força é a vitória na guerra, com ela ou com a ameaça da sua aplicação. O que se espera nesse nível é abrir o caminho para a execução dos fins pelos quais a política estabeleceu essa relação de força, dito de outra maneira, retirar a capacidade de combate e a vontade de resistir do inimigo. No caso do terrorismo, o objetivo estratégico é sempre provocar terror, aquele pavor incontrolável que produz nas pessoas a sensação de vulnerabilidade e de exposição à violência homicida. $\mathrm{O}$ terrorismo manifesta sua singularidade no nível estratégico: diferentemente de outras ações de violência política, essa forma de violência não emprega seus meios táticos para lograr a vitória na guerra nem a tomada do poder, mas 
provocar um pânico incontrolável na população ou em uma parte definida dessa. Por tanto, o objetivo estratégico do terrorismo, que o distingue de qualquer outra relação de força e o define, é provocar terror.

(iii) Nível político: neste nível realizam-se os objetivos pelos quais se leva a cabo uma guerra. A política escolhe o inimigo; define a lógica e temporalidade da guerra e as formas de retorno à paz; realiza os acordos e calcula os custos que serão impostos ao vencido; sobre tudo, ela se realiza na imposição da vontade para a qual os meios diplomáticos resultaram impotentes e tornaram a guerra viável. No caso do terrorismo não há imposição da vontade, mas apenas a procura da fratura da vontade do inimigo. Como não objetiva a tomada do poder (o terrorista típico não deseja o poder político, mas apenas destruí-lo) não pode pretender impor a sua vontade, pelo menos não a sua vontade positiva, mas a sua vontade negativa, a desestabilização do inimigo, o desmembramento do tecido social, a falência do Estado. Nem todos os grupos terroristas têm ou perseguem fundamentos políticos, o grupo japonês acima referido, com seu objetivo especificamente milenarista, é um exemplo. Por tanto, é difícil definir o terrorismo pela sua finalidade política, como o seria qualquer outro tipo de relação de força, inclusive a guerra. Raymond Aron dizia que uma guerra se define pela caracterização política dos beligerantes e pelas formas de retorno à paz. No caso do terrorismo essa definição é inaplicável: é difícil caracterizar politicamente os terroristas (que nem beligerantes são, em sentido estrito) e não existe a possibilidade de se pensar no retorno à paz.

Em função dessa tripartição proposta do fenômeno do terrorismo, podemos pensar na diferente natureza que a vítima desse tipo de acionar assume para cada um dos três níveis de análise. Assim, para o nível tático, estratégico e político poderemos encontrar:

(i) A vítima tática, é a vítima direta, o morto, o esfaqueado, o assassinado, o mutilado, o explodido, o sequestrado, enfim, aquele que sofre na sua própria pessoa a violência do atentado e deixa sua vida no mesmo ou por ele é diretamente afetado;

(ii) A vítima estratégica são todos aqueles que sobrevivem ao atentado, mas que se sentem de alguma maneira incluídos no grupo de risco dos vitimados. Eles não são atingidos diretamente pelo atentado, mas sabendo-se vulneráveis e sujeitos à possibilidade de serem a próxima vítima tática, são presas do pânico. Essa é a vítima visada pelo terrorista: a que não morre e permanece viva e aterrorizada e na qual culmina o objetivo estratégico dessa forma particular de violência;

(iii) Embora possa não ter objetivos políticos, o terrorismo pode e normalmente tem uma vítima política: é o Estado, aquela instituição que deveria garantir a vida dos seus cidadãos, para o qual recolhe pesados tributos com $o$ argumento e a justificativa de montar uma estrutura capaz de assegurar a vida, a propriedade e a tranquilidade de todos os cidadãos.

Note-se que a vítima preferencial do terrorismo, a vítima estratégica, não é o morto, que aqui denominamos "vítima tática". Inegavelmente o terrorista procurará provocar o maior dano possível e por tanto tentará executar a maior quantidade possível de vítimas no nível operacional tático. Porém, se o objetivo estratégico é provocar um pânico incontrolável, obviamente a vítima estratégica não pode ser nunca a vítima tática, aquela que perde a sua vida no atentado, por uma questão eminentemente ontológica: os mortos não temem. Com efeito, a vítima objetivada estrategicamente pelo terrorismo não é o morto que tomba no atentado, mas aqueles que ficam vivos e conscientes de que podem ser a próxima vítima tática. O fundamento do terror não é a morte, mas a insegurança que provoca a certeza da sua vulnerabilidade ante o impiedoso acionar 
do terrorista. O fundamento do terror é o sentimento inequívoco de desamparo ante a vontade do terrorista.

\section{Classificação do terrorismo}

${ }^{14}$ Para uma visão mais pormenorizada dessa classificação ver Bonanate (1986).

15 Já foram desmantelados vários intentos de contrabandear material nuclear, em pequenas doses, para a Europa, aparentemente vindos da ex-URSS. Em maio de 1992 já advertíamos para essa possibilidade: "O gelo da guerra fria derreteu e sua água radioativa penetrou a porosidade ideológica do mundo [...] O controle nuclear do Leste, caracterizado pela 'racionalidade' burocrática, hoje se dilui em vários gatilhos nas mão de líderes tão populistas quanto imprevisíveis" (Saint-Pierre 1992, p. 2).

${ }^{16}$ As armas nucleares e biológicas já estão ao alcance dos grupos terroristas. Nada impedirá, chegado o caso, que esses grupos as usem. $\mathrm{O}$ exemplo do metrô de Tóquio e também do prédio de Oklahoma são a constatação de que o terrorismo não tem limites éticos para atingir seus objetivos.
Vários autores propõem classificações tipológicas de terrorismo obedecendo a diferentes critérios. Em função do sujeito do terrorismo, por exemplo, pode-se tipificá-lo a partir da pergunta "quem é o terrorista?" Nesse caso é possível agrupar as ações como individuais, quando o atentado é realizado por um indivíduo isolado e sem ligação com nenhuma organização; grupais, quando a autoria do atentado é atribuído a organizações que podem ser políticas, religiosas, étnicas etc.; finalmente, estatais, quando na origem do terrorismo ou como seu autor material se encontra o próprio Estado. Conforme o âmbito no qual o terrorismo espalhe o terror, pode-se classificar como terrorismo nacional (seja esse terrorismo de Estado ou antiestatal), quando realizado no âmbito do próprio Estado. Será considerado terrorismo internacional, quando seu objetivo vise um contexto político internacional, como no caso das guerras de libertação contra as formas de ocupação do inimigo ${ }^{14}$. Finalmente, pode-se falar de terrorismo transnacional quando, pela possibilidade de mobilizar recursos humanos e materiais, os grupos terroristas atuam em países alheios ao de sua população de origem (Reinares 1998, especialmente o capítulo 5).

Tendo em conta a modalidade do atentado, pode se distinguir o terrorismo sexual, psicológico, econômico, militar etc. Pela consideração dos meios, o terrorismo pode ser perpetrado com qualquer tipo de armas, desde as brancas como nos simbólicos degolamentos na Argélia, até bombas de diferentes poder de explosão. Além disso, com o atentado no metrô de Tóquio, ficou claro que as armas químicas não estão excluídas nas ações do terrorismo e, seguindo essa lógica, podemos concluir que armas biológicas e também atômicas possam fazer parte do arsenal do terror ${ }^{15}$ : isto é, armas de destruição em massa (ADM) em mãos do terrorismo, inclusive na sua forma transnacional (Hoffman 1999, especialmente o capítulo 7) ${ }^{16}$.

Em função dos alvos visados, ordenados pela pergunta "para quê?", poderíamos falar de terrorismo patológico, quando não há um objetivo claro, mas o motivo da ação é de ordem psicopatológica, como na maioria dos atentados individuais; religioso, quando o objetivo é aniquilar um grupo religioso ou provocar a adesão religiosa por meio do medo; econômico, quando o efeito procurado é nessa área, como no caso do terrorismo contra os turistas, em países onde o turismo é a principal fonte de renda, ou contra fontes de energia etc.; e político, quando o objetivo visado são as relações de força, como quando se mata uma personagem política importante, como no assassinato de J. F. Kennedy em 1963, quando era presidente dos EUA.

Dada a impossibilidade de analisar os terrorismos desde seus objetivos políticos (que pode não ter), ou desde sua metodologia (que pode apresentar uma variação extenuante), mesmo dos seus instrumentos (porque pode ser qualquer um, até um avião de passageiros, por exemplo), desde meus primeiros textos sobre esse tema me posicionei em uma abordagem de análise que considerava a particularidade da vítima. Assim, incialmente propus um critério classificatório baseado na particular seleção da vítima por parte do terrorista, conforme procure intencionalmente precisão identificatória da mesma ou não e, em função do qual, pode-se distinguir dois tipos específicos de terrorismo: o discriminado ou sistemático e o indiscriminado ou aleatório. 


\section{V.1. Terrorismo sistemático ou discriminatório}

${ }^{17}$ Sobre o terrorismo do ETA, pode-se consultar Shabad e Ramo (1995)
Chamei de "terrorismo sistemático ou discriminatório" àquele que escolhe suas vítimas por alguma característica específica que as identifica, seja essa a religião, a profissão, a "cor", a etnia, a classe social etc. Atentados terroristas com essa característica eram, por exemplo, os cometidos pelo Movimento Separatista Basco (ETA) ${ }^{17}$; pelo Exército Republicano Irlandês (IRA); pelos argelinos pertencentes ao braço armado da Frente Islâmica de Salvação (FIS) especialmente contra jornalistas e formadores de opinião; pelos comandos palestinos do Hamas, contra postos militares israelitas (Hoffman 1999, caps. $3 \mathrm{e}$ 4) pelos ataques da aviação israelita sobre acampamentos palestinos; pela guerrilha colombiana, contra companhias petroleiras estrangeiras. Esse tipo de ação terrorista baseia sua eficácia na correta precisão da identificação da vítima, pois é a partir dessa identificação que os campos da amizade e da inimizade assumem seus contornos políticos com maior nitidez, obrigando a sociedade a tomar partido por um ou outro dos campos.

$\mathrm{O}$ que todas estas ações têm em comum é que, ainda que esses grupos possam procurar em última instância a tomada do poder, em nenhum caso essas operações terroristas são decisivas. Porém, todas elas se revestem de uma significação muito clara: identificar o inimigo; tornar nítida à frente de combate; manifestar abertamente a opção desse grupo pela luta armada; levar seu inimigo a tomar consciência de que sua posição não é invulnerável; disseminar a intranquilidade e o terror entre seus membros para forçar a deserção pelo medo e a perda de prestígio da instituição. A diferença entre esse terrorismo sistemático e o aleatório é que, se com a discriminação do inimigo no primeiro estabelecem-se os campos da inimizade, no segundo o inimigo não é identificado, não estabelece campos de confronto, não há frente de combate, ele apenas provoca uma comoção social desintegradora: o espanto.

O terrorismo sistemático, diferentemente do aleatório, pode ser uma ferramenta para a luta política na medida em que galvaniza o âmbito social em campos de combate, mas em contrapartida o risco é de desvincular o grupo armado da mobilização popular. Como nota Carlos Nuñez (1969, p. 63):

"Um princípio revolucionário e uma exigência prática: suas ações [refere-se às dos Tupamaros, grupo guerrilheiro uruguaio operante nos fins dos 60 e aniquilado nos primeiros anos dos 70] golpeiam o sistema e os interesses que ele representa, mas evitam provocar vítimas inocentes com o que ganhariam a rejeição da população".

Com efeito, frequentemente as ações terroristas tornam-se contraproducentes para as forças políticas que fazem uso tático delas no confronto armado assimétrico, na medida em que podem desatar uma violência maior e indiscriminada por parte das forças da repressão. O castigo descarregado sobre os movimentos populares como forma de retaliar os atentados terroristas, acompanhados de uma profusa campanha de propaganda, pode levar à direção política desse movimento a colocar-se contra o acionar terrorista. Ainda que isso não se concretize, as forças repressivas podem tomar os atentados terroristas como pretexto para reprimir e desarticular a organização dos movimentos sociais. As ações terroristas podem fortalecer o acionar das organizações populares, auxiliar na sua defesa, apoiá-las nas negociações, mas também pode ser desastrosa quando utilizada como motivo ou justificativa da repressão. Em alguns processos revolucionários ela contribuiu com as formações populares para fomentar o ódio, necessário para manter acesa a chama revolucionária, mas tentando evitar a todo custo espalhar o medo entre elas. Essa foi a difícil e controvertida função do terrorismo nos movimentos revolucionários: fornecer segurança, coesão e ódio às forças populares e terror às fileiras do aparelho repressivo. Esse fato não foi negligenciado por "Che" Guevara (1984, p. 52): 
"Há um ponto sumamente controvertido na apreciação do terrorismo. Muitos consideram que ao se usar e exacerbar a opressão policial, impede todo contato mais ou menos legal ou semiclandestino das massas e impossibilita sua união para as ações que seriam necessárias em um momento determinado. Isso, em si, é exato, mas sucede também que, nos momentos de guerra civil e em determinadas populações, a repressão do poder governante é tão grande que, de fato, está suprimida toda classe de ação legal e é impossível uma ação de massas que não seja apoiada pelas armas".

\section{V.2. Terrorismo indiscriminado ou aleatório}

${ }_{18}$ A natureza espetacular do atentado terrorista, sua repercussão nos meios de comunicação de massa e a necessidade dessa divulgação para a efetividade do ato terrorista são muito bem analisados por Hoffman (1999, pp. 194-235). Ver também Wardlaw (1984, pp. 144-164).

19 Veja-se, entre outros, Faria e Teixeira (1993).
O terrorismo é aleatório ou indiscriminado quando sua vítima não é claramente definida nem obedece a uma seleção sistemática. Esse tipo de terrorismo procura deliberada e indiscriminadamente vitimar inocentes, em grande número e com a maior diferenciação social possível. O atentado terrorista ideal dessa tipologia é conseguir matar, num único ato, homens e mulheres, velhos, jovens e crianças, brancos e negros, militares, sacerdotes, pessoas comuns: não definir "grupo de risco" delimitado, qualquer um pode ser a próxima vítima. Não há atividade, idade, profissão, credo, “cor", ideologia, posição política que esteja isento da possibilidade de ser o alvo do atentado.

A universalidade da vítima é a característica principal do terrorismo aleatório, outra é a "espetacularidade" e a visibilidade global do atentado ${ }^{18}$. O momento escolhido é normalmente a plena luz do dia e quando o movimento de pessoas é maior. O lugar às vezes é representativo da ordem social imperante, como tribunais, supermercados, lojas, prédios onde funcionam repartições públicas (as Torres Gêmeas e o Pentágono), meios de transporte coletivos (como o metrô de Tóquio), enfim, lugares de grande concentração ou circulação de pessoas. A morte de crianças indubitavelmente inocentes, como no atentado perpetrado no edifício de Oklahoma, onde funcionava uma creche, permite mostrar que não há lugar para a piedade, que o terrorista é inclemente e precisa manifestá-lo. Seu objetivo é criar um terror incontrolável e generalizado. O cidadão vê em qualquer outro possível terrorista como inimigo. Quando o terrorismo aleatório é eficaz, todo mundo é suspeito e, como não há identificação política nem ideológica, sua repressão é muito difícil sem cair num também indiscriminado terrorismo de Estado.

O efeito principal desse tipo de terrorismo é fazer com que o cidadão se sinta abandonado por parte do Estado; que perceba que nada pode fazer para se defender, que não controla a situação, que o Estado não pode garantir sua segurança e tranquilidade: é o que chamamos "desamparo aprendido". Tomamos essa expressão de um modelo animal usado para estudar doenças mentais, especialmente a depressão. O modelo é construído a partir da sujeição do animal à técnica do choque incontrolável, isso é, à aplicação de choques elétricos de intensidade e frequência variáveis, mas inescapáveis. Depois de se debater por algum tempo e procurar a fuga por todos os meios, o animal desiste da fuga, aprendendo que qualquer intento é inútil. Esse é o momento em que o animal aprende que está desamparado, constituindo-se no modelo de depressão. O notável é que, a partir desse momento, o animal não procurará a fuga inclusive em situações em que essa seja possível ${ }^{19}$. No caso que estamos analisando, o terrorismo funcionaria como os choques elétricos, seus atentados são aleatórios, de intensidade variável e de frequência incerta; como o Estado não tem condições de garantir a segurança do cidadão, para esse a situação apresenta-se como “inescapável". Como o cidadão não pode fazer nada para se salvar do atentado, para garantir sua exclusão da possibilidade de ser a próxima vítima, ele cai em desamparo. Nesse sentido, o cidadão sente-se desprotegido e vulnerável ao ataque imprevisível e indiscriminado do terrorismo. Ele sente que o Estado, com suas estruturas preventivas e repressivas, é impotente para protegê-lo. Se o 
soberano, depositário de todas as vontades e forças, não pode cumprir a mínima contrapartida que o contrato social dele exige a saber, a proteção da vida do cidadão, então perde a legitimidade, o elemento de coesão afrouxa-se e o tecido social se abre até deixar o cidadão sozinho e aterrorizado.

O terrorismo não tem como objetivo direto a tomada do poder, nem poderia tê-lo. Seu objetivo direto é a desestabilização do regime vigente por meio do terror induzido na população. Por isso, quanto mais irracional e aleatório seja seu acionar, mais eficiente será. Esse tipo de terrorismo, diferentemente do sistemático, não identifica um inimigo, não define âmbitos de inimizade, não projeta frentes de combate, apenas procura provocar uma comoção social desintegradora: o espanto.

Obviamente, o combate contra estes dois tipos específicos de terrorismo se articula em estratégias diferentes. A seletividade e o compromisso político do primeiro constitui sua debilidade e o ponto de abertura para a inteligência contra-terrorista. Como esse tipo de terrorismo é o empregado tanto pelo Estado (como as forças armadas em certas operações de combate), como pelas forças políticas insurgentes, há uma lógica que busca claramente debilitar as forças opositoras (estatais, políticas, forças armadas ou combatentes insurretos) e, ao mesmo tempo, evitar ações que provoquem seu desprestígio e consequente debilitação pela perda de apoio da opinião pública. Como com esse tipo de atos terroristas se procura deliberadamente criar uma frente de combate, uma divisão entre amigos e inimigos, é possível, em determinadas circunstâncias, estabelecer combate. No outro caso de tipo de terrorismo, por ser indiscriminado, sua força reside na sua aleatoriedade. Como não funda uma divisão clara para que se possa optar entre amigos e inimigos (todos são seus inimigos), não constitui um fenômeno político, e seu combate é dificultado. Esse tipo de terrorismo que foge da identificação da vítima e portanto sua própria identificação política (se a tiver), torna impotentes o combate e o emprego de forças armadas. Neste caso, a inteligência e o seguimento financeiro são os meios mais indicados para o enfrentamento. Porém, evitar situações de injustiça e desespero, que tornem a vida um preço aceitável a pagar como vetor letal da vingança, diminuindo as tensões e injustiças sociais continua sendo o melhor antídoto do terrorismo que, salvo o caso do terrorismo patológico, sempre é reativo.

Note-se que boa parte das definiçõos correntes de terrorismo lhe associam um componente político. No caso do terrorismo indiscriminado não há possibilidades de considerar esse componente, pelo que rejeitamos essas definições que simplesmente criminalizam grupos políticos armados e ocultam a verdadeira natureza que facilitaria o acesso a uma teoria do terrorismo e permitiria melhorar as condições para combater um ou outro tipo de terrorismo. $\mathrm{Na}$ verdade esse erro consiste em substantivar em indivíduos ou grupos sociais o adjetivo "terrorista" que só se aplica com rigor a tipos específicos de ações de força (tácticas) que procuram estrategicamente causar espanto em algum subgrupo social ou na sociedade como um todo. O emprego substantivado do termo "terrorista" só tem funcionalidade política descriminante para a repressão sem limites morais. Do ponto de vista epistêmico, pouco ou nada importa.

\section{Análise do 11 de Setembro de 2001}

Os acontecimentos de 11 de Setembro de 2001 colocaram os cidadãos norte-americanos na situação de desamparo descrita, isso é, ficaram surpresos, atônitos, sentindo pela primeira vez na pele a vertiginosa sensação da vulnerabilidade. No seu próprio país perceberam que o seu Estado, o mais poderoso do mundo, era impotente para protegê-lo desse terrível flagelo global e difuso, sem rosto, sem bandeira, sem frente de combate, sem ostentação e sem clemência. No primeiro momento o ataque alcançou seu objetivo, subsumiu o país na 
mais profunda soçobra e os seus cidadãos no desamparo. $\mathrm{O}$ ataque inscreve-se no tipo que chamei "terrorismo aleatório". Procurou-se deliberadamente a maior quantidade possível de vítimas táticas. Todo norte-americano sentiu-se incluído no "grupo de risco". A vítima tática, o morto, o mutilado, não teve qualquer sentido estratégico. A vítima estratégica não são os três ou quatro mil mortos caídos no atentado, mas os milhões de norte-americanos que ficaram vivos e aterrorizados.

O desamparo padecido pelo cidadão norte-americano afrouxou o tecido social que não apenas não lhe fornecia segurança, mas que o comprometia existencialmente. Ele percebe que seu Estado, com o exército mais poderoso do mundo, não podia garantir sua vida em sua própria casa, sentindo-se desamparado. O tecido social se desintegrou corroendo a legitimidade do poder. Assim é como o terrorismo atinge seu objetivo político que, insisto, não é a tomada do poder, mas simplesmente sua desestabilização. A vítima política do atentado é o Estado norte-americano. Daí o grito marcial do presidente norteamericano George Bush convocando à "guerra contra o terrorismo" e "aquele país que não se comprometa com essa guerra será considerado inimigo e combatido até a morte". O grito de guerra do presidente Bush teve naquele momento um duplo sentido político: por um lado, manifestar que ainda havia um Estado que chegaria até as últimas consequências para proteger seus cidadãos, que estes achariam, como sempre, segurança sob as asas da águia americana cujas garras não descansariam até achar os agressores onde for que se escondessem; por outro lado, procurou insuflar a confiança no cidadão de que sua única proteção é o amparo desse Estado. Assim, com essa dupla mensagem, o presidente conseguiu fechar novamente o tecido social, elevou o espírito do povo norte-americano devolvendo-lhe a esperança. Com esses resultados logrou o objetivo político desse grito: recuperar a tensão social e a moral do povo.

Se, por um lado, Bush logrou recompor a confiança política do povo norte-americano, por outro, conseguiu submergir o mundo na soçobra e insegurança. Internamente desorganizou o desenho da projeção estratégica, alterou a doutrina da defesa nacional e o treinamento dos seus soldados. Externamente golpeou mortalmente a ONU desmoralizando suas deliberações; relativizou a densidade jurídica das relações internacionais erodindo os pilares da sociedade internacional: o respeito às soberanias nacionais e a não intervenção nos assuntos internos. Levou a cabo e estimulou intervenções armadas unilaterais e a rebeldia da ONU em vários pontos do mundo, pelos mais diversos motivos nunca justificados e menos comprovados. Trivializou e vulgarizou o conceito de "terrorista" que foi empregado longamente para rotular qualquer posição adversa, não apenas aos interesses dos Estados Unidos, mas também foi aproveitada a moda por muitos governantes que acharam uma excelente oportunidade para reprimir seus adversários sem qualquer contenção moral. A ambiguidade tanto conceptual quanto jurídica é funcional àqueles que tem condições de impor sua interpretação semântica ou jurídica pela força, mas é fatal para a previsibilidade necessária que permite manter relações sociais estáveis, tanto nacionais quanto internacionais.

\section{Conclusões}

Hoje, tanto o substantivo "terrorismo" quanto o adjetivo "terrorista" são empregados sem qualquer cuidado e com objetivos políticos e/ou repressivos. Qualquer emprego tático assimétrico de força é considerado "terrorismo" e a quem o emprega, "terrorista". Confunde-se conceitos que descrevem fenômenos tão diversos como "guerra de guerrilha", "operações especiais", "insurreição", "guerra de libertação" ou "guerra revolucionária" sob o manto nebuloso do mal definido termo de "terrorismo". Esse emprego indiscriminado 
e arbitrário dificulta a compreensão do fenômeno, o acesso explanatório ao mesmo e, ainda mais grave, seu eventual enfrentamento. Hoje, grupos políticos em armas, como as FARC-EP, o movimento Liga Islâmica do Iraque e o Levante (LIIL), que atualmente ocupa boa parte do Iraque, a resistência de libertação no Afeganistão, todos eles empregando tanto a tática da guerra de guerrilha quanto de atos terroristas são catalogados arbitrariamente como terroristas. Os meio de comunicação de massa reproduzem essa arbitrariedade e muitos "acadêmicos" consolidam acriticamente o erro nos seus escritos. O próprio fato de um movimento armado ocupar espaço, seja numa estratégia de posição, seja de movimento, desqualifica-o como movimento terrorista, não obstante possa apelar a atos terroristas como tática de amedrontar a resistência do seu inimigo. Os terroristas não ocupam espaço, não abrem frente de combate, não fixam posição: o objetivo estratégico do terrorismo é causar um medo incontrolável, o terror.

Defendo o emprego do termo "terrorista" apenas como adjetivo para qualificar certas ações violentas que visam aterrorizar e diminuir a resistência do adversário para abrir caminho à decisão estratégica que conduza à realização do objetivo político. Assim, as ações terroristas seriam apenas táticas e nunca estratégicas, o que permite identificar um ator político com um objetivo político e não um ato radical cujo alvo estratégico seja simplesmente aterrorizar para desfibrilar o tecido social. As definições extensionais correntes de "terrorismo", por carecer de um elemento essencialmente definicional, permite a decisão política, portanto arbitrária, da inclusão ou não de grupos políticos no conjunto dos grupos de "terroristas". Dessa forma, os terroristas serão aqueles incluídos no conjunto dos "terroristas", assim como os que fazem parte desse conjunto serão os considerados terroristas. Há quem se conforme com a circularidade dessa definição. Para alguns ela é funcional para combater adversários sem limites morais sobre os meios empregados; outros a aceitam como vítimas da preguiça intelectual; finalmente, não faltam os que a admitem em troca da efêmera fama que brinda a visibilidade da notícia. Todavia, aqueles que ainda professam algum compromisso acadêmico não podem menos que se incomodar intelectualmente com essa falta de rigor de definição.

O combate ao terrorismo é possível. Negar essa possibilidade significa declarar a impotência da estratégia. Mas a guerra não é a forma adequada de enfrentar nem o meio militar é o mais eficaz para se aproximar da vitória. Se bem é certo que a inteligência financeira e policial pode auxiliar no desmonte de grupos terroristas e dissuadi-los da sua intenção, também há formas políticas de diminuir as tensões e ódios, de antecipar e resolver os conflitos "antes de que as labaredas cheguem à cidadela". Quatro dias antes dos atentados, numa apresentação realizada em Washington (Saint-Pierre 2001b), premonitoriamente defendi que o governo de um país com pretensão à liderança mundial não podia rasgar, como fez os Estados Unidos, em menos de duas semanas, sete tratados internacionais referidos à segurança de todos os habitantes da Terra como, por exemplo, o tratado sobre pequenas armas, sobre controle de armas químicas, biológicas e nucleares, sobre o controle de emissão de poluentes etc. Defendi, naquela oportunidade, que uma potência líder não podia ficar de costas aos muitos conflitos do mundo que colocam em risco a segurança internacional e que poderiam ser politicamente resolvidos de forma feliz. Particularmente com relação ao conflito entre palestinos e israelenses, central na estabilidade do Oriente Médio, e que apenas pela intermediação política e pressão diplomática dos Estados Unidos as forças de ocupação israelense se retirariam dos territórios palestinos para voltar a se sentar à mesa e recuperar os canais de negociação pacíficos. Bastaria que os Estados Unidos deixassem de obstruir as propostas de resoluções da ONU sobre o Estado de Israel para que esse abandonasse suas práticas de terrorismo de Estado, o que retiraria um dos motivos alegados pela 
odiosa resposta assimétrica palestina, último gesto que resta aos esquecidos do Direito Internacional ante sua impotência militar convencional. Ao final, "tampouco devemos nos espantar de que os povos cometam vinganças inusitadas contra os que violentam sua liberdade" - são as palavras de Maquiavel nos Discorsi que nenhuma potência pode ignorar.

Héctor Luis Saint-Pierre (hector.sp@uol.com.br) é Doutor em Filosofia pela Universidade Estadual de Campinas (Unicamp) e Professor Titular do Programa Interinstitucional de Pós-Graduação em Relações Internacionais "San Tiago Dantas" (Unesp, Unicamp e PUC-SP).

\section{Referências}

Arendt, H. 1985. Da violência. Brasília: Editora da UnB.

Bonanate, L. 1986. Terrorismo político. In: N. Bobbio, ed. Dicionário de Política. Brasília: Editora da UnB.

Faria M.S.; Teixeira, N.A. 1993. Reversal of Learned Helplessness by Chronic Lithium Treatment at a Prophylactic Level. Brazilian Journal of Medical and Biological Research, 26(11) pp. 1201-1 212.

Guevara, E. 1984. Obras completas. Buenos Aires: Ediciones Metropolitanas.

Hobbes, T. 1983. Leviatán. Madrid: Editora Nacional.

Hoffman, B. 1999. A mano amada. Historia del terrorismo. Madrid: Ediciones Espasa Calpe.

Jobin, N., ed. 2010. Segurança internacional. Perspectivas brasileiras. Rio de Janeiro: FGV.

La Maisonneuve, E. 1998. La metamorfosis de la violencia. Ensayo sobre la guerra moderna. Buenos Aires: Grupo Editor Latinoamericano.

Montoya, A. 2010. As teorias da guerra preventiva e as Relações Internacionais. São Paulo: Editora da Unesp.

Nuñez, C. 1969. Tupamaros: la única vanguardia. Montevideo: Provincias Unidas.

Reinares, F. 1998. Terrorismo y Antiterrorismo. Barcelona: Ediciones Paidós Ibérica.

Saint-Pierre, H. 1991. Inimigo e Excepcionalidade na teoria da soberania de Carl Schmitt. Impulso, 5(9). 1992. A nova (des)ordem mundial. O Estado de S. Paulo, 19 maio.

2000. A política armada. Fundamentos da guerra revolucionária. São Paulo: Editora da Unesp. 2001a. Até tu, Arafat? Jornal do Brasil, 14 set.

2001b. La reaparición de los militares en la escena política latinoamericana. Trabalho apresentado no XXIII International Congress do Latim American Studies Associations. Washington, D.C.

2002. La centralidad del concepto de "enemigo" en la teoría de la soberania de Carl Schmitt. In J. Dotti; J. Pinto, eds. Carl Schmitt: su época y su pensamento. Buenos Aires: Ed. EUDEBA.

2004. Guerra de todos contra quien? La necesidad de definir terrorismo. In R. Lopez, ed. Escritos sobre Terrorismo. Buenos Aires: Prometeo

2009. Fertilidade heurística da abordagem vitimológica para a análise do Terrorismo. In A. Zhabit; C. Texeira da Silva, eds. Neoterrorismo: reflexão e glossário. Rio de Janeiro: Gramma.

Saint-Pierre, H.; Bigatão, J. 2008. Las mutantes mascaras de Marte. In A.M. Tamayo, ed. Conocer la Guerra, construir la seguridad. Aproximaciones desde la sociedad civil. Lima: IDL.

Schmitt, C. 1984. El concepto de lo político. Buenos Aires: Folio.

Shabad, G.; Ramo, F.J.L. 1995. Political Violence in a Democratic State: Basque Terrorism in Spain. In M. Crenshaw, ed. Terrorism in Context. Pennsylvania: Pennsylvania State University Press.

Trotsky, L. 1973. Escritos militares. Ejército, milicias, guerrillas. Buenos Aires: Amaicha.

Walzer, M. 2001. Guerras justas e injustas. Un razonamiento moral con ejemplos históricos. Barcelona: Ediciones Paidós Ibérica.

Wardlaw, G. 1984. Political Terrorism. Cambridge (UK): Cambridge University Press.

Wilkinson, P. 1977. Terrorism and the Liberal State. London: Macmillan.

\section{Outras fontes}

Brasil. 2014. Discurso da Presidenta da República, Dilma Rousseff, na abertura da $67^{a}$ Assembleia Geral das Nações Unidas.

$$
\text { Palácio }
$$

do

Planalto.

Disponível

em: http://www2.planalto.gov.br/acompanhe-o-planalto/discursos/discursos-da-presidenta/discurso-da-presidenta-da-repub lica-dilma-rousseff-na-abertura-da-67a-assembleia-geral-das-nacoes-unidas-nova-iorque-eua. Acesso em: 1 fev 2015. 


\section{Abstract}

In this article I discuss the generally accepted definition of "Terrorism" by considering it extensional and not intentional. The danger of doing so is that from it derives political decisions that lead to the use of force. The lack of objectivity and applicable criteria of the extensional definition makes of it an arbitrary characterization and of your applicability a decision merely political. Besides ontological and epistemological issues of this arbitrary way of defining, it darkens the strategic drawing and makes it more difficult to effectively face this threat. I call the attention for the political use of this word, more frequently used to criminalize groups and social protesters movements, because in this way it is intended to legitimize all types of means of combating, including torture. Because of this I propose to limit the use of the word "terrorist" as an adjective that qualify certain violent actions and avoid using it as a noun referring to groups and strategies. Finally I propose the victimologic approach to the study of terrorism because of its heuristic fertility and explanatory capacity of certain forms of violence.

KEYWORDS: terrorism; September 11; International Security; political violence; War on Terror.

License information: This is an open-access article distributed under the terms of the Creative Commons Attribution License, which permits unrestricted use, distribution, and reproduction in any medium, provided the original work is properly cited. 